\title{
Partisan Bias in Economic News Content: New Evidence ${ }^{12}$
}

\author{
****Forthcoming in American Politics Researcb**** \\ Eric Merkley \\ Ph.D. Candidate \\ Department of Political Science \\ University of British Columbia \\ Email: eric.merkley@alumni.ubc.ca \\ Address: 1866 Main Mall - C425 \\ Vancouver, BC, Canada V6T 1Z1
}

\footnotetext{
${ }^{1}$ Many thanks to Mark Pickup, Alan Jacobs, Stuart Soroka, Éric Bélanger, and Dominik Stecula for their helpful comments and advice at several stages of this research project. And, thank you to Tim Hicks, Alan Jacobs, and Scott Matthews for allow me access to their alternative measure of tone in economic news content for use in supplementary analyses.

2 The supplementary appendix, data, and replication code will be available on the author's personal website (http:/ / www.ericmerkley.com)
} 


\begin{abstract}
Claims that the mainstream media are biased in favor of the Democratic Party are commonplace. However, empirical research has yielded mixed results and neglected potential bias in the dynamics of media behavior and the exploration of observable implications of a biased media environment. This paper contributes to this literature by using time series analyses of the dynamics in media tone based on over 400,000 stories on inflation and unemployment from top-circulating American print media and the Associated Press newswire. The results suggest there is bias in favor of Democratic presidents. Media tone in unemployment and inflation coverage is more favorable during Democratic presidencies after controlling for economic performance. Tone is also generally more responsive to negative, short-term changes in economic conditions during Republican presidencies. In other words, bias is stronger with worsening economic conditions.
\end{abstract}


The media have their critics. Scholars for decades have noted systemic biases that exist in agenda setting and framing (Iyengar \& Kinder, 1987; Shoemaker \& Vol, 2009). Journalists are prone to report on the news in ways that emphasize drama and novelty at the expense of context (Bennett 1988), and negative information rather than positive developments (Altheide, 1997; Harrington, 1989; Soroka, 2006, 2012). Another possibility is that the media may have partisan bias against a particular party while in office. Most prominent is the suspicion among conservative commentators and activists that journalists are unlikely to report the news in a way that is fair to both parties because they largely identify with the Democratic Party (see Baron (2006) for a theoretical model of journalist-driven bias). This contention is supported empirically by some scholars using a variety of methods (Ansolabehere et al., 2006; Groseclose \& Milyo 2005; Lott \& Hassett, 2014; Schiffer, 2006), but others have found no such pattern in news reporting (D’Alessio \& Allen, 2000; Gentzkow \& Shapiro, 2010; Niven, 2002; Puglisi \& Snyder, 2015; Watts et al., 1999). The jury is still out on whether there is pro-Democratic bias in the mainstream media.

Part of the problem is that there are substantial challenges to measuring partisan media bias. Most early efforts sought to measure fundamental characteristics of news coverage, like its tone or volume, and look for differences in the treatment of Republican and Democratic administrations or candidates. However, these differences may or may not be deserved depending on the performance of administrations while in office or the candidates on the campaign trail. The analyses in this paper measure tone in economic news coverage across a large number of high circulating American newspapers and use objective economic performance as a baseline to evaluate the fairness of this coverage, an approach followed by previous scholars (Niven, 2002; Lott \& Hassett, 2014). More precisely, it examines whether media tone in economic news is more negative during Republican administrations after controlling for economic performance.

The analyses presented here, however, take a step further in testing for the implications of a biased press and it is here where it makes its main contribution to the literature. The media's bias toward novelty and negativity mean that economic news coverage focuses on short-term changes in the economy at the expense of long-term trends, and on negative rather than positive economic developments (Nadeau et al., 1999; Soroka, 2006, 2012; Soroka et al., 2015). Thus, this paper will examine whether the media are more responsive to negative changes in the economy during Republican presidential terms. In short, this paper integrates research on media bias with work on media responsiveness to the economy. In so doing, it will offer evidence that the economy is covered more negatively during Republican presidencies after controlling for performance and that this is particularly true when short-term economic conditions worsen. 


\section{Partisan Slant in the News Media}

Allegations of bias in the press are not new. Academic and non-academic analysts have attempted to determine whether these claims are justified. Formal models identify several possible sources of bias: journalists who tend to identify with the Democratic Party (Baron, 2006), media ownership (Balan, DeGraba, \& Wickelgren, 2009), and reader preferences (Gentzkow \& Shapiro, 2010). ${ }^{3}$ The implications are that media bias may be either liberal, conservative, or heterogeneous depending on which factor is at work.

Empirical studies of media bias have been similarly mixed. There have been four main approaches used thus far. First, many early studies simply compared differences in coverage tone or volume across administration and in doing so have found results ranging from the null (Watts et al., 1999) to liberal bias (Schiffer, 2006). A comprehensive review of this early literature by D'Alessio and Allen (2000) shows that the majority of them produced null results. More recently, work by Budak, Goel, and Rao (2016) used crowdsourced hand coding to measure tone of coverage towards Republicans and Democrats in political news across 15 different outlets. They found coverage to be largely neutral, though bias did appear in the form of disproportionate criticism of one side - even in non-editorial content. These studies, however, cannot address the fact that coverage may well be deserved depending on the behaviour of politicians or the comparative performance of Democratic and Republican administrations.

Second, scholars have looked for bias in newspaper endorsements. On the one hand, Democratic candidates receive endorsements over 10 percent of the time more than Republicans (Ansolabehere et al., 2006). On the other hand, endorsements on ballot initiatives appear to centre on the median voter in their circulation base (Puglisi \& Snyder, 2015). However, there are strong reasons to suspect that endorsement decisions may be less at the discretion of journalists than of outlet ownership. Even if endorsements do indeed centre on the mean of an outlet's readers, bias may still subtly creep into the tenor of news coverage, which is more at the discretion of journalists themselves.

\footnotetext{
${ }^{3}$ There is substantial evidence that suggests journalists strongly lean towards the Democratic Party. For instance, a Pew poll found that self-identified liberals outnumbers conservatives 5 to 1 among national journalists - a margin that has widened over time (http://www.people-press.org/2004/05/23/bottomline-pressures-now-hurting-coverage-say-journalists/). Journalists are also heavy contributors to the Democratic Party (see Bonica, 2014).
} 
Third, researchers have evaluated media bias through the construction of slant scores using the relative citations of left-wing and right-wing think tanks (Groseclose \& Milyo, 2005), or loaded political phrases associated with the Democratic or Republican Party (Gentzkow \& Shapiro, 2010). These approaches have generally found that media sources tend to slant to the left, but Gentzkow and Shapiro (2010) argue that this may be due to reader tastes, as their measure of newspaper slant is correlated with the ideological slant of the circulation base. There are important limitations to the use of slant scores. They are a bit distant from the fundamental characteristics of news coverage, like tone and volume, which most people see as indicating possible bias. More importantly for our purposes here, these approaches have been found to be fragile over time (Gasper, 2011), which makes them of limited use in trying to explain over time dynamics in newspaper coverage.

Finally, recent scholarship has looked at differences in story coverage across administrations while controlling for objective measures of performance. Larcinese, Puglisi, and Snyder (2011) discover evidence of partisan bias in the responsiveness of story selection in the media on unemployment, the federal budget, and the trade deficit, but not inflation. That is, they finding Democratic-endorsing newspapers give more coverage to Republican presidents with poor economic performance. Niven (2002) measures bias by comparing newspaper coverage of Democratic and Republican presidents and governors who perform equally well on unemployment and crime, respectively. He sees little evidence of bias against Republicans in office, but is limited to comparing across two presidential administrations. Lastly, a more recent paper by Lott and Hassett (2014) examine tone in economic news headlines when economic indicators are released to the public. They show that Democratic administrations get more positive coverage when controlling for performance. Coverage of valence issues like the state of the economy present a unique opportunity to test for differences in certain features of news content across administrations while holding performance on these issues constant.

This paper will follow the approach of these latter scholars with a focus on examining the differences in the tone of coverage across presidential administrations after controlling for objective economic performance. It is possible that media owners have a direct role in shaping content, which might generate media bias against Democratic administrations. However, most literature has found effects that range from the null to bias against Republicans, so the hypotheses that follow are formulated accordingly. The analysis, however, will be able to address both possibilities.

H1: Media tone in economic news coverage is systematically more negative when Republicans hold the White House after controlling for economic performance. 


\section{Partisan Bias and the Dynamics of Economic News}

Previous approaches have focused on examining static differences in tone, slant, or endorsements. These approaches get us some way in allowing us to observe important differences in coverage between outlets or across administrations. An important limitation is that they do not fully take into account how journalists are likely to report the news. This is particularly problematic for approaches that measure underlying characteristics of news stories like tone. Journalists are reactive in their reporting to changes in their environment. For this reason, we also might want to be attentive to dynamics in news coverage. This is particularly striking in the domain of economic news, where the media are broadly responsive to objective economic indicators (Soroka et al., 2015). For example, tone becomes more positive as conditions improve and coverage volume increases as conditions worsen.

But we also know that this responsiveness is biased in important ways. For one, the media are much more responsive to negative news than to positive news (Altheide, 1997; Harrington, 1989; Soroka, 2006, 2012). In part, this is due to editorial determinations of newsworthiness and a reaction to audience

preferences (Soroka, 2006; Trussler \& Soroka, 2014), which may be slanted towards negativity for reasons of evolutionary psychology (Soroka, 2014). But, it could also be a manifestation of the media acting as watchdogs to raise alarms during times of poor economic performance (Soroka, 2006). It is not surprising, then, that bias towards negative news has been found in economic coverage. Media content is systematically more responsive to increases in the unemployment rate than decreases in the rate, for instance (Soroka, 2012).

For another, the media are biased towards drama and novelty at the expense of covering long-term trends and chronic conditions (Bennett, 1988). As Nadeau and his colleagues note: "Not only do media reports emphasize change, they also stress the importance and significance of the observed change. Rather than reporting change as a temporary deviation from the norm, changes are reported as an indication of the development or the aggravation of a trend" $(1999,118)$. The obvious implication of this observation for economic news is that the media may be more responsive to short-run changes in economic conditions rather than long-run fluctuations in these indicators (Nadeau et al., 1999; Soroka, 2012). In other words, coverage may make more out of the fact that there was a drop of 0.5 points in the unemployment rate in a month rather than the fact the overall rate is at 7 percent. This has been found to indeed be the case in the tone of economic news coverage, but not in its volume (Soroka et al., 2015). 
This is all to say that if partisan bias in the press exists, it should map onto what we know about how journalists react to and report on new information, or, for the purposes of this paper, how they respond to new economic developments. Their tendency to react to negative, short-term changes in the economy should be stronger during Republican presidencies if there is partisan bias. This could be because, as Soroka (2006) suggests, economic news content partially serves a watchdog function. Democratic-leaning journalists may be reluctant to shower negative news on their party in the White House. In short, if bias exists, it should be stronger with a worsening economy.

H2: Media tone in economic news coverage is systematically more responsive to negative, short-run changes in economic conditions during Republican presidencies.

\section{Data and Methods}

The following analyses use news coverage of unemployment and inflation to examine the responsiveness of the news media's tone to incumbent performance on these issues. Some discussion is needed on justifying their use. Unemployment was chosen because it has been a focus of the scholarly literature on the responsiveness of the media (Soroka, 2006, 2012) and the public to economic conditions (Powell \& Whitten, 1993; Carlsen, 2000). Unemployment coverage can serve as a useful proxy for economic news more broadly. ${ }^{4}$ More importantly for our purposes, unemployment is a valence issue where there is broad agreement that lower levels of unemployment are preferable to higher levels. It may be a sign of bias if unemployment news coverage is more positive for one party after controlling for unemployment performance.

There are, however, distributional implications of unemployment. It disproportionately affects lower income Americans. In light of this, the Democratic Party has typically "owned" this issue because it primarily affects voters in their electoral coalition (Petrocik, 1996). We might be concerned that bias may reflect this issue ownership. Journalists, like the public, may be more or less inclined to reward and punish a party in government if they expect a certain policy outcome (see Powell \& Whitten, 1994;

\footnotetext{
${ }^{4}$ A measure of media tone similar to the one used in this paper was constructed by Hicks, Jacobs, Matthews, and Merkley (HJMM) on a sample of general economic news. This measure and the unemployment-specific variant used in this paper are highly correlated (0.56). Further, there is support for $\mathrm{H} 1$ and $\mathrm{H} 2$ using their measure. More details can be found in section B of the supplementary materials.
} 
Petrocik, 1996; Petrocik, et al., 2003). In this case, the expectation that Democrats will perform more effectively on unemployment - their salient goal - may produce bias that is not partisan in nature, but specific to the issue. Selecting issues with different partisan owners would help rule out bias that varies across this dimension.

Thus, inflation was selected as a second issue for analysis as it has distributional implications opposite to those of unemployment. Inflation is typically seen as an issue owned by the Republican Party because it disproportionately harms creditors and erodes the savings of high income Americans. Other economic issues, like growth, are not as clearly aligned with the priorities of the Republican Party to the exclusion of Democrats. Findings of bias that are consistent across "most different" cases like unemployment and inflation may bolster the generalizability of the findings. ${ }^{5}$

This paper uses coverage of unemployment and inflation in 23 high-circulating American newspapers and the Associated Press (AP) newswire. The selection of newspapers was based on a list of the top-50 newspapers by circulation from the Alliance for Audited Media, and those available for download on LexisNexis Academic and Lexis. In total, the newspaper sources have a circulation base of over 17 million households. The AP, for its part, is perhaps the most influential media organization in the United States, as it provides content to over 1,300 newspapers and television broadcasters. Table S1 in the supplementary materials provides the sources used with their start dates in parentheses. They represent a broad range of sources from different regions of the country and that have varied histories of editorial endorsements, ranging from the solidly Democratic New York Times, to the reliably Republican Dallas Morning News.

There are two notable gaps in the source selection. Online news outlets were omitted because the empirical strategy requires significant over time variation. As such, these analyses provide evidence that can only generalize to traditional, mainstream outlets. More importantly, transcripts from the three big broadcasters (ABC, CBS, and NBC) were omitted from the following analysis for a couple of reasons. First, prior research has shown that newspaper coverage strongly shapes television broadcasts (Roberts \& McCombs, 1994; Blood \& Phillips, 1999). Second, analyses in section A of the supplementary materials

\footnotetext{
${ }^{5}$ Inflation, for its part, can also be seen as a performance indicator where low levels are preferred to high levels. There is important, robust debate on what constitutes an optimal level of inflation in economics and policy circles, but, nonetheless, there is strong evidence that the media is responsive to inflation performance (Table 2), and, in the supplementary materials, that public economic evaluations are strongly conditioned by inflation (Table S2).
} 
show that the tone of television broadcasts on unemployment is not strongly associated with either public economic evaluations or objective measures of economic performance, in stark contrast to newspapers and newswire. As a major focus of this paper is in exploring biased responsiveness to economic conditions, this is problematic. ${ }^{6}$

Articles were downloaded from LexisNexis using a battery of search terms related to each topic. The search protocol can be found in Figure S1 in the supplementary materials. Newspaper articles were excluded if their section heading indicated that they were found in the editorial or opinion section of the newspaper since we are not interested in bias among commentators. Otherwise, they were included in the sample since Americans receive information about the economy from a wide variety of newspaper sections. ${ }^{7}$

Our primary dependent variable of interest is tone in unemployment and inflation coverage, which is most closely associated with changes in the public's evaluation of the economy (Soroka et al., 2015). ${ }^{8}$ Tone was measured using the Lexicoder Sentiment Dictionary (LSD) using the automated content analysis software Lexicoder, which extracts counts of words in preprogrammed dictionaries. The LSD has 6016 words that are coded for positive or negative connotations. The dictionary, and Lexicoder itself, has undergone substantial testing and it has been found comparable to the use of human coders in the domain of economic news (see Young \& Soroka (2012) and supplementary information in Soroka (2012)). It has also been used extensively in coding tone related to economic news to great effect (Soroka et al., 2015), and appears to outperform other dictionaries that are tailored towards economic news content (Wlezien et al., 2017). This software, and the accompanying sentiment dictionary, offer a useful tool to analyze large amounts of media coverage in a short amount of time.

\footnotetext{
${ }^{6}$ We cannot rule out the possibility that this is due to noise in our measure of broadcast tone - a result of far fewer observations per period compared to newspapers and newswire. In either case, it makes using broadcast news in these analyses problematic. There is, however, some evidence in the supplementary materials in support for H1 in broadcast coverage (Tables S14 and S15).

${ }^{7}$ Section headings vary considerably across sources, so it would be difficult to apply consistent criteria to include or exclude specific sections across the entire sample in any case. The results found here are likely robust to different inclusion criteria. For example, results are similar using the HJMM economic news tone measure, which excludes the entire business section (Table S5).

${ }^{8}$ Volume does not influence economic evaluations, nor does it moderate tone's effect on public economic evaluations. More details are in the supplementary materials in section E, Table S10.
} 
The measure was constructed by counting the positive and negative words in each article and subtracting the percentage of negative words from the percentage of positive words. Not only does this measure take account of "charged" words, it also weights the score by the amount of neutral content. This score is then averaged quarterly across all articles for each outlet. The final tone measure represents an average of the tone of AP content on the one hand, and newspaper content taken together on the other. The unemployment and inflation tone series and the analyses presented in this paper run from 1985 to 2013, spanning eight presidential terms and five different administrations. Sections A and C of the supplementary materials show that the tone measure of unemployment strongly tracks with public evaluations of the economy as we would expect and that this likely reflects the influence of the media on these evaluations rather than the reverse.

There are two main measures of economic outcomes used in this paper. Inflation performance was measured with seasonally-adjusted, averaged annual CPI-based inflation rate for urban consumers, while unemployment conditions was captured with seasonally-adjusted unemployment rates. Both measures were collected from the Federal Reserve of St. Louis's FRED Database. Average media tone appears to be responsive to both the level and short-run changes in inflation, and short-run changes in unemployment. 9

The hypotheses from above were tested using time series analyses estimated with ordinary least squares regression and heteroskedastic-robust standard errors. Perhaps the most flexible approach to estimate the effect of both short-run and long-run changes in economic indicators is the use of the generalized error correction model (GECM). This option, appropriate for the stationary data used here, allows for the estimation of a short-run impact of a change in economic conditions on media tone, while showing the degree to which this change impacts the equilibrium level of media tone in the long-run. In other words, it distinguishes short-run effects that disappear after time $t$ from long-term effects on the dependent variable. The media's responsiveness to the economy in its tone of coverage is found primarily in the short-run. These models will use the tone measure for inflation and unemployment averaged across all newspapers on the left hand-side.

There are three main models. The first model tests for whether coverage of the economy is more positive or negative under Democratic presidents estimated with OLS. It is as follows:

\footnotetext{
${ }^{9}$ Plots of tone and economic indicators can be found in the supplementary materials in Figures S3 and S4. Distributions of the variables are found in Table S8 and the results of unit root tests are in Table S9, both in section $\mathrm{D}$. All variables are trend-stationary.
} 
$\Delta$ Tone $_{\mathrm{t}}=\alpha_{0}+\delta_{1}$ Tone $_{\mathrm{t}-1}+\beta_{1} \Delta$ Perform $_{\mathrm{t}}+\beta_{2}$ Perform $_{\mathrm{t}-1}+\beta_{3}$ President $_{\mathrm{t}}+\beta_{4} \Delta \mathrm{Z}_{\mathrm{t}}+\beta_{5} \mathrm{Z}_{\mathrm{t}-1}+\varepsilon_{\mathrm{t}}$

Where current changes in tone are regressed on lagged tone, current changes in performance indicators and their lagged levels, and a dummy variable for Democratic control of the White House, along with changes and first lags of control variables $(Z)$, and an error term. Of primary interest here is whether presidential partisanship influences the overall level of tone in economic news articles. These effects can be calculated by dividing the coefficient on the presidential variable with the negative value of the error correction coefficient $(\delta)$. Standard errors for the cumulative long-run effect can be collected after applying the Bewley transformation. ${ }^{10}$ The cumulative long-run effect of $\beta_{3}$ should be positive and significant in order to provide support for H1. If it is negative and significant, it would suggest a bias against Democratic administrations

The second model shown in equation 2 tests for biased responsiveness of media tone to economic indicators. It is as follows:

$\Delta$ Tone $_{\mathrm{t}}=\alpha_{0}+\delta_{1}$ Tone $_{\mathrm{t}-1}+\beta_{1} \Delta$ Perform $_{\mathrm{t}}+\beta_{2}$ Perform $_{\mathrm{t}-1}+\beta_{3}$ President $_{\mathrm{t}}+\beta_{4} \Delta$ Perform $_{\mathrm{t}}{ }^{*}$

President $_{\mathrm{t}}+\beta_{5} \Delta \mathrm{Z}_{\mathrm{t}}+\beta_{6} \mathrm{Z}_{\mathrm{t}-1}+\varepsilon_{\mathrm{t}}$

Here $\beta_{1}$ gives the short-run effect of changes in the indicator of interest under a Republican presidency. $\beta_{4}$ gives the additive effect of moving to a Democratic president, for short run changes in that indicator. We would expect a significant negative coefficient on $\beta_{1}$ and a significant positive coefficient on $\beta_{4}$ to provide support for $\mathrm{H} 2$, and the opposite if the bias is against Democratic presidents. ${ }^{11}$

An alternative specification for equation 2 can make use of the true zero point in changes in economic indicators to separate the effects of improving and deteriorating economic conditions. This is shown in equation 3 below. We know the media is primarily responsive to short-run increases in indicators like unemployment and inflation, so bias should manifest itself with responsiveness to worsening conditions. In this case, we would expect significant coefficients on $\beta_{1}$ and $\beta_{5}$, signed in opposite directions, to support $\mathrm{H} 2$.

${ }^{10}$ The Bewley transformation requires estimating the equation: $Y_{t, n}=\alpha_{0}+\beta_{1} \Delta Y_{t}+\beta_{2} X_{t}-\beta_{3} \Delta X_{t}+\varepsilon_{t, n}$, where $\beta_{2}$ is the long-run effect estimated with a standard error, while $\Delta \mathrm{Y}$ can be proxied by using predicted values from the equation $\Delta \mathrm{Y}_{\mathrm{t}, \mathrm{n}}=\alpha_{0}+\beta_{1} \mathrm{Y}_{\mathrm{t}-1}+\beta_{2} \mathrm{X}_{\mathrm{t}}+\beta_{3} \Delta \mathrm{X}_{\mathrm{t}}+\varepsilon_{\mathrm{t}, \mathrm{n}}$.

${ }^{11}$ A more general model would interact the long-run effect and presidency. This interaction, however, is insignificant. In the interest of efficiency and due to the fact I do not have a theoretical interest in that interaction, the restriction has been imposed in each of our models. 
$\Delta$ Tone $_{\mathrm{t}}=\alpha_{0}+\delta_{1}$ Tone $_{\mathrm{t}-1}+\beta_{1} \Delta$ Worsen $_{\mathrm{t}}+\beta_{2} \Delta$ Improve $_{\mathrm{t}}+\beta_{3}$ Perform $_{\mathrm{t}-1}+\beta_{4}$ President $_{\mathrm{t}}+$

$\beta_{5}$ Improve $_{t}^{*}$ President $_{t}+\beta_{6}$ Worsen $_{t}{ }^{*}$ President $_{t}+\beta_{7} \Delta Z_{t}+\beta_{8} Z_{t-1}+\varepsilon_{t}$

Control variables were added to deal with potential confounders. Most important are controls for other economic indicators. There is some trade-off between unemployment and inflation in the macroeconomy, and scholars have noted the Democratic and Republican parties make this trade-off differently (Carlsen, 2000; Hibbs, 1987; Powell \& Whitten, 1993). Unemployment rates are controlled for in the inflation models, and vice versa. These are added as changes and lagged levels. Changes and levels of a composite index of leading indicators (CLI) from the OECD to control for residual economic performance not captured by the unemployment and inflation measures. It is also possible that performance varies between parties while in office for non-economic issues. Tone resulting from such asymmetries in performance may seep into economic news. So, Gallup's presidential job approval rating, averaged by quarter, will be added into each model as changes and lagged levels. The data is available at the American Presidency Project hosted by the University of California, Santa Barbara. ${ }^{12}$ Finally, all models include a linear trend as our measures are trend stationary. ${ }^{13}$

\section{Results}

Column 1 in Tables 1 and 2 present the results of parsimonious models that test the impact of our economic indicators on tone of articles on unemployment and inflation, respectively. Unemployment, primarily affects media tone in the short-run. A one point increase in the unemployment rate is expected to decrease media tone by 0.19 points in the short-run or one standard deviation $(\mathrm{p}<0.05)$. There is no meaningful or significant long-run effect. This is in keeping with previous work that finds the media react primarily to short-term changes in unemployment rather than long-run conditions. The media appear to be responsive both to short-run changes in inflation and the inflation rate in the long-run, however. A short-run increase in the inflation rate of one point is expected to decrease tone by 0.15 points or 0.58

${ }^{12}$ http://www.presidency.ucsb.edu/data/popularity.php.

${ }^{13}$ Although section $C$ provides little evidence of a significant endogenous relationship between media tone and public economic evaluations, this is far from settled in the literature. Media bias could reflect similar in the general public. Public economic evaluations were controlled in supplementary analyses to demonstrate the robustness of the results. These results are displayed in section $G$ of the supplementary materials. 
standard deviations $(\mathrm{p}<0.01)$. An increase in the inflation rate of one point is also expected to cumulatively decrease tone by 0.24 points in the long-run as well or one standard deviation (Inflation $\mathrm{t}_{-1} /\left[-1 *\right.$ Tone $\left._{\mathrm{t}-1}\right]$ ).

Table 1. OLS Regression Estimates, Unemployment

\begin{tabular}{|c|c|c|c|c|c|c|c|c|}
\hline & \multicolumn{2}{|l|}{1} & \multicolumn{2}{|l|}{2} & \multicolumn{2}{|l|}{3} & \multicolumn{2}{|l|}{4} \\
\hline & Coef. & SE & Coef.. & SE & Coef. & SE & Coef.. & SE \\
\hline Tone $_{\mathrm{t}-1}$ & $-0.59 * * *$ & 0.08 & $-0.68 * * *$ & 0.09 & $-0.72 * * *$ & 0.09 & $-0.72 * * *$ & 0.10 \\
\hline$\Delta$ Unemployment & $-0.19 * *$ & 0.08 & $-0.13^{*}$ & 0.07 & $-0.27 * * *$ & 0.10 & & \\
\hline Unemployment $_{-1}$ & -0.01 & 0.01 & -0.01 & 0.01 & -0.01 & 0.01 & -0.01 & 0.01 \\
\hline Democratic President $_{t}$ & & & $0.09 * * *$ & 0.03 & $0.11 * * *$ & 0.04 & 0.02 & 0.05 \\
\hline$\Delta$ Inflation & $-0.06 * * *$ & 0.02 & $-0.05^{* *}$ & 0.02 & $-0.06^{* * *}$ & 0.02 & $-0.08^{* * *}$ & 0.03 \\
\hline Inflation $_{\mathrm{t}-1}$ & $-0.09 * *$ & 0.04 & -0.06 & 0.04 & -0.04 & 0.04 & -0.01 & 0.04 \\
\hline$\Delta \mathrm{CLI}$ & $0.11 * * *$ & 0.04 & $0.12 * * *$ & 0.03 & $0.11 * * *$ & 0.03 & $0.12^{* * *}$ & 0.03 \\
\hline CLI ${ }_{t-1}$ & -0.01 & 0.02 & 0.00 & 0.02 & 0.01 & 0.02 & 0.02 & 0.02 \\
\hline$\Delta$ Presidential Approval & -0.00 & 0.00 & -0.00 & 0.00 & -0.00 & 0.00 & -0.00 & 0.00 \\
\hline Presidential Approval $_{\mathrm{t}-1}$ & $-0.00 *$ & 0.00 & $-0.00^{*}$ & 0.00 & $-0.00^{*}$ & 0.00 & $-0.00^{*}$ & 0.00 \\
\hline$\Delta$ Unemployment $^{*}$ President $_{\mathrm{t}-1}$ & & & & & $0.26^{* *}$ & 0.13 & & \\
\hline Improve & & & & & & & 0.08 & 0.16 \\
\hline Improve $^{*}$ President $_{\mathrm{t}}$ & & & & & & & $-0.44^{*}$ & 0.24 \\
\hline Worsen & & & & & & & $-0.40 * * *$ & 0.15 \\
\hline Worsen $*$ President $_{\mathrm{t}}$ & & & & & & & $0.62^{* * *}$ & 0.16 \\
\hline Constant & 1.33 & 2.54 & 0.29 & 2.43 & -0.32 & 2.40 & -0.95 & 2.47 \\
\hline Trend & Yes & & Yes & & Yes & & Yes & \\
\hline $\mathrm{N}$ & 115 & & 115 & & 115 & & 115 & \\
\hline $\mathrm{R} 2$ & 0.41 & & 0.4 & & 0.47 & & 0.52 & \\
\hline
\end{tabular}

Heteroskedastic-robust standard errors; ${ }^{*} \mathrm{p}<0.1,{ }^{*} \mathrm{p}<0.05,{ }^{* *} \mathrm{p}<0.01$

Column 2 in Tables 2 and 3 test for potential unconditional bias in media coverage of the economy by introducing a dummy variable for Democratic control of the White House (H1). Unemployment coverage is 0.09 points more positive during Democratic presidents after controlling for performance or 0.47 standard deviations $(\mathrm{p}<0.01)$. The cumulative long-run effect of having a Democratic president is 0.14 points or 0.70 standard deviations (Democratic President $\mathrm{t}_{\mathrm{t}-1} /\left[-1 *\right.$ Tone $\left._{\mathrm{t}-1}\right]$ ). The story is almost identical for inflation. Inflation coverage is over 0.15 points more positive during Democratic presidencies after controlling for performance or 0.58 standard deviations $(\mathrm{p}<0.01)$. The cumulative long-run effect of having a Democratic presidency is 0.19 points or 0.79 standard deviations (Democratic President $_{\mathrm{t}-1} /\left[-1 *\right.$ Tone $\left.\left._{\mathrm{t}-1}\right]\right)$. The analyses for both inflation and unemployment provide strong support for H1. 
Table 2. OLS Regression Estimates, Inflation

\begin{tabular}{|c|c|c|c|c|c|c|c|c|}
\hline & \multicolumn{2}{|l|}{1} & \multicolumn{2}{|l|}{2} & \multicolumn{2}{|l|}{3} & \multicolumn{2}{|l|}{4} \\
\hline & Coef. & SE & Coef. & $\mathrm{SE}$ & Coef. & SE & Coef. & $\mathrm{SE}$ \\
\hline Tone $_{\mathrm{t}-1}$ & $-0.64 * * *$ & 0.07 & $-0.78 * * *$ & 0.07 & $-0.76^{* * *}$ & 0.07 & $-0.76^{* * *}$ & 0.07 \\
\hline$\Delta$ Inflation & $-0.16 * * *$ & 0.04 & $-0.15^{* * *}$ & 0.03 & $-0.17 * * *$ & 0.03 & & \\
\hline Inflation $_{\mathrm{t}-1}$ & $-0.18 * * *$ & 0.05 & $-0.16 * * *$ & 0.05 & $-0.12 * * *$ & 0.05 & $-0.13^{* *}$ & 0.06 \\
\hline Democratic President $_{\mathrm{t}}$ & & & $0.17 * * *$ & 0.04 & $0.16^{* * *}$ & 0.04 & $0.12^{* *}$ & 0.06 \\
\hline$\Delta$ Unemployment & $-0.26 * *$ & 0.11 & -0.15 & 0.10 & $-0.22^{* *}$ & 0.11 & $-0.22 * *$ & 0.11 \\
\hline Unemployment $_{\mathrm{t}-1}$ & $-0.03^{*}$ & 0.01 & $-0.03 * *$ & 0.01 & $-0.03^{* *}$ & 0.01 & $-0.03 * * *$ & 0.01 \\
\hline$\Delta \mathrm{CLI}$ & $0.14^{* * *}$ & 0.04 & $0.17 * * *$ & 0.04 & $0.18^{* * *}$ & 0.04 & $0.17 * * *$ & 0.04 \\
\hline $\mathrm{CLI}_{\mathrm{t}-1}$ & -0.03 & 0.03 & -0.01 & 0.02 & -0.01 & 0.02 & -0.01 & 0.02 \\
\hline$\Delta$ Presidential Approval & -0.00 & 0.00 & $-0.01 *$ & 0.00 & $-0.01 * *$ & 0.00 & $-0.01 * *$ & 0.00 \\
\hline Presidential Approval $\mathrm{t}-1$ & -0.00 & 0.00 & -0.00 & 0.00 & -0.00 & 0.00 & -0.00 & 0.00 \\
\hline$\Delta$ Inflation $^{*}$ President $_{\mathrm{t}-1}$ & & & & & $0.21 * *$ & 0.09 & & \\
\hline Improve & & & & & & & $-0.15^{* * *}$ & 0.03 \\
\hline Improve $^{*}$ President $_{\mathrm{t}-1}$ & & & & & & & 0.12 & 0.18 \\
\hline Worsen & & & & & & & $-0.25^{* * *}$ & 0.09 \\
\hline Worsen $*$ President $_{\mathrm{t}}$ & & & & & & & $0.29 * *$ & 0.15 \\
\hline Constant & 4.09 & 2.90 & 2.09 & 2.66 & 1.72 & 2.63 & 1.82 & 2.58 \\
\hline Trend & $\mathrm{Ye}$ & & $\mathrm{Ye}$ & & $\mathrm{Ye}$ & & $\mathrm{Ye}$ & \\
\hline $\mathrm{N}$ & 115 & & 115 & & 115 & & 11 & \\
\hline $\mathrm{R} 2$ & 0.4 & & 0.5 & & 0.5 & & 0.5 & \\
\hline
\end{tabular}

Heteroskedastic-robust standard errors; ${ }^{*} \mathrm{p}<0.1,{ }^{*} \mathrm{p}<0.05,{ }^{* *} \mathrm{p}<0.01$

\section{Biased Media Responsiveness}

What about bias in the responsiveness of media tone to the state of the economy? Column 3 in Table 1 shows that a short-run increase in the unemployment rate of one point leads to a decrease in tone of 0.27 points during Republican presidencies 1.35 standard deviations $(\mathrm{p}<0.01)$. This effect is eliminated under Democratic presidencies $(\mathrm{p}<0.01)$. The linear predictions are plotted in panel A of Figure 1. Column 4 shows that this effect is particularly strong when unemployment conditions worsen. A percentage point increase in the unemployment rate reduces tone by 0.40 points or two standard deviations $(p<0.01)$. This effect vanishes under Democratic presidents $(p<0.01)$. Tone also increases as conditions improve, but only during Democratic presidencies. A one point decrease in the unemployment rate increases tone by 0.36 points $(\mathrm{p}<0.1)$, while there is no effect when Republicans hold the White House. The linear predictions are plotted in panel B of Figure 1. 

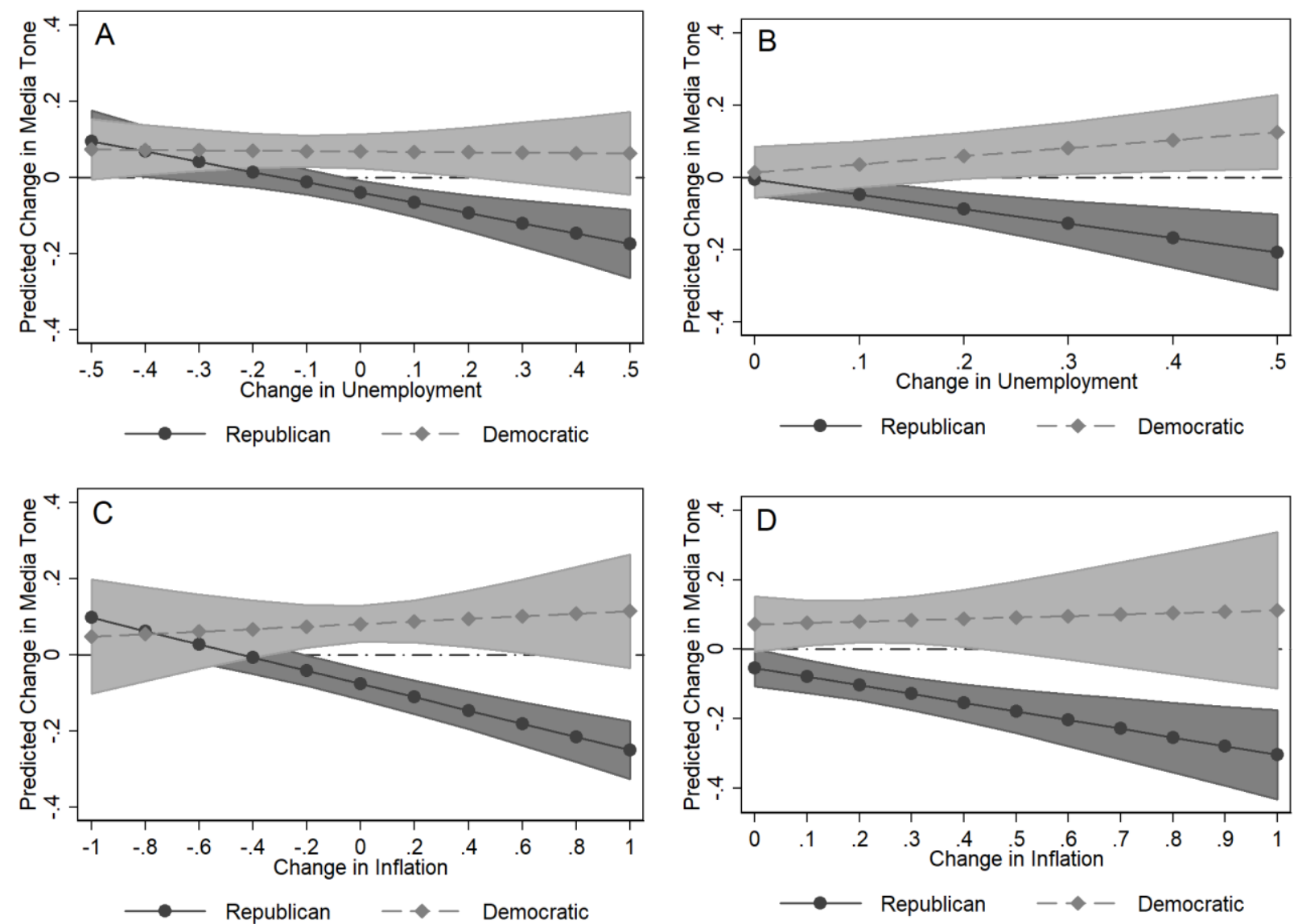

Figure 1. Linear predictions of media tone for short-run changes in unemployment (A) and for shortrun positive changes in unemployment (B). Linear predictions of media tone for short-run changes in inflation (C) and for short-run positive changes in inflation (D). Note: $90 \%$ confidence intervals.

And what of inflation? Column 3 in Table 2 shows that media tone is primarily responsive to shortrun changes in inflation under Republican presidents. An increase in inflation of one percentage point is expected to reduce tone by 0.17 points in the short-run or 0.65 standard deviations $(p<0.01)$. This effect is eliminated under Democratic presidents $(\mathrm{p}<0.05)$. The linear predictions from this model are plotted in the panel $\mathrm{C}$ of Figure 1.

There is also some evidence that the biased responsiveness against Republicans exists more strongly during worsening conditions as shown in model 4. A short-run increase in the inflation rate of one point is expected to decrease tone by 0.22 points during Republican presidencies or 0.85 standard deviations $(p<0.05)$. This effect vanishes under Democratic presidents $(p<0.10)$. In contrast, there is no evidence that Republicans are rewarded with more favorable tone for improvements in the inflation rate, however. Media responsiveness to Republican performance is asymmetric. The linear predictions of this model are 
plotted in panel D of Figure 1. The results for both inflation and unemployment taken together provide strong support for $\mathrm{H} 2$. The tendency of media to be particularly responsive to negative news in the shortrun is much weaker during Democratic presidencies.

\section{Extensions}

The results presented above provide compelling support for the notion that the media are biased against Republicans in office, and that this is due in large part from a lack of attentiveness to deteriorating economic performance during Democratic administrations. Extensions to these analyses provide additional support for this finding. First, scholars have focused attention on agenda setting and article volume as an indicator of possible bias. As indicated above, article volume does not appear to shape public opinion on the economy independent of tone. However, we might still expect bias in coverage volume if it is driven by negative news. The results of models estimated with article volume on the left hand side are shown in section E of the supplementary materials. Article volume, as found in previous work, is generally more responsive to long-run conditions rather than short-run changes. In the long-run, coverage volume is more responsive to economic conditions during Republican presidencies compared to Democrats for both unemployment and inflation.

Second, we might be concerned that the sample of newspapers used in this paper doesn't reflect the tilt of the overall media environment. These sources were selected for their influence and high circulation, but a majority of them do consistently endorse Democratic presidential candidates. Section F of the supplementary materials present the results of panel analyses where our measures of interest are interacted with the newspaper's presidential endorsement in a given period. The results show that the static bias in favor of Democratic presidents (H1) is found only among Democratic-endorsing newspapers. In contrast, Republican-endorsing newspapers display no bias, rather than bias against Democratic administrations. The biased dynamics found in this paper (H2), however, are consistent regardless of newspaper endorsement. The sample of media used here is limited to mainstream sources. The inclusion of outlets from the conservative media echo chamber would likely change the results considerably. However, among mainstream outlets, it does not appear that Republican-endorsing newspapers effectively counterbalance the bias of their Democratic-endorsing counterparts.

\section{Discussion}

There has been substantial literature devoted to assessing the merits of allegations of partisan bias in mainstream media. The most prominent of these claims is that the press is tilted in a liberal direction due to the partisan sympathies of a large majority of journalists (Baron, 2006). However, there are many 
factors operating in newsroom environments that make it debatable whether this bias will manifest itself in practice. Perhaps the most important among them is that editors are tasked with providing content that sells. This plays in to several other biases that scholars have noted contaminate news content, such as novelty (Bennett, 1988) and negativity (Soroka, 2012). Slanted news content may alienate important segments of news consumers.

There are also considerable methodological challenges with measuring bias. Foremost among them - how do we know when differences in coverage between Republican and Democratic administrations and candidates are deserved? The implication is that equal and balanced coverage, in some circumstances, may be better classified as having bias, while reporting that on its face looks slanted may be fair. If Republican presidents receive systematically lower tone because unemployment tends to be higher on their watch that might mean journalists are doing their job. If this gap in tone still exists after accounting for differences in economic performance, it might be another story entirely. Note that this conception of bias makes monitoring by editors quite difficult. They need to engage in counterfactual reasoning - what would our coverage look like for an identical level of performance with a different party in the White House? The difficulty in engaging in such counterfactuals, along with the possibility for very subtle differences in tone to exist, may leave plenty of room for partisan bias to seep into coverage.

This paper follows recent literature in conceiving of bias as the difference in coverage of Republicans and Democratic administrations with equivalent levels of performance. There are not many domains where this can be put to a clean test. So this paper makes use of economic news, or more precisely unemployment and inflation, which have two clear and widely used objective metrics of performance - the inflation and unemployment rates. If differences in coverage persist between Democratic and Republican administrations after controlling for these indicators and other measures of performance, this provides some evidence of partisan bias in media coverage. This is exactly what the analysis presented in this paper shows. Consistent with $\mathrm{H} 1$ and in line with the findings of Lott and Hassett's (2014) analysis of news headlines, the tone of economic news coverage is decidedly more positive during Democratic presidencies after controlling for performance.

The main contribution of this paper, however, is in testing for other implications of journalistdriven partisan bias that have received little attention in literature thus far. Empirical tests for bias have not sufficiently accounted for how journalists report the news - in particular, their responsiveness to negative news and short-term changes. We should expect a biased press to be more responsive to negative, short-term changes during Republican presidencies (H2). This is exactly what was found. And, it was consistent across issues, ruling out an issue ownership effect in the media's responsiveness to 
economic performance. ${ }^{14}$ In a way, this echoes the finding of Budak, Goel, and Rao (2016) that bias is found less in the praise of one side than in the disproportionate criticism of the other side.

So what does this mean for the media information environment where most Americans acquire economic information? The extensions described here and elaborated on in the supplementary material (section F) suggest the mainstream media environment as a whole may tilt in favor of the Democratic Party. Republican-endorsing outlets do not appear to counterbalance the bias found among their Democratic-endorsing counterparts. The Associated Press, a major source of content for newspapers and broadcasters alike, appears to grant more favorable economic news coverage during Democratic presidencies, as do the major national broadcasters (section G). Taken together, the outlets examined in this study represent a significant and influential portion of mainstream news media environment.

Future work should also expand the number of sources used to analyze tone and broaden the number of economic issues under study to examine the degree to which the bias identified here prevails elsewhere. It would also be fruitful to use other potential indicators of bias like the volume of coverage or in headlines using this approach which will allow analysts to engage with a broader assortments of media outlets for a similar cost. More importantly, however, researchers must grapple with the data generating process in news content to arrive at more theoretically-driven predictions of bias. This paper took a turn in this direction by predicting stronger bias with worsening economic conditions, but other directions can certainly be followed. Relatedly, greater focus should be placed on investigating real-world implications of having a biased media environment rather than simply analyzing sources themselves. Only then can researchers begin to reconcile the wide range of findings in this research program, which is essential in an age of declining trust in the mainstream media.

\section{References}

Altheide, D. L. (1997). The news media, the problem frame, and the production of fear. Sociological Quarterly, 38, 647-668.

Ansolabehere, S., Lessem, R., \& Snyder Jr., J. M. (2006). The orientation of newspaper endorsements in U.S. elections, 1940-2002. Quarterly Journal of Political Science, 1, 393-404.

${ }^{14}$ Robustness tests can be found in section $G$ of the supplementary materials. They include the results from estimations omitting the lagged dependent variable, adding dummies for all recessions through the period, controlling for public economic evaluations, and estimating results for newspaper, AP, and broadcast news separately. 
Balan, D. J., DeGraba, P., \& Wickelgren, A. L. (2009). Ideological persuasion in the media. Mimeo, Federal Trade Commission.

Baron, D. (2006). Persistent media bias. Journal of Public Economics, 90, 1-36.

Bennett, L. W. (1988). News: The politics of illusion (2nd ed.). New York: Pearson Longman.

Blood, D. J., \& Phillips, P. C. B. (1995). Recession headline news, consumer sentiment, the state of the economy and presidential popularity: A time series analysis 1989-1993. International Journal of Public Opinion Research, 7, 2-22.

Bonica, A. (2014). Mapping the ideological marketplace. American Journal of Political Science, 58, 367-386.

Budak, C., Goel, S., \& Rao, J. M. (2016). "Fair and balanced? Quantifying media bias through crowdsourced content analysis.” Public Opinion Quarterly, 80, 250-271.

Carlsen, F. (2000). Unemployment, inflation and government popularity - Are there partisan effects?” Electoral Studies, 19, 141-150.

D’Alessio, D., \& Allen, M. (2000). Media bias in presidential elections: A meta-analysis. Journal of Communication, 50, 133-156.

Gasper, J. T. (2011). Shifting ideologies? Re-examining media bias. Quarterly Journal of Political Science, 6, 85-102.

Gentzkow, M., \& Shapiro, J. M. (2010). What drives media slant? Evidence from U.S. daily newspapers. Econometrica, 78, 35-71.

Groseclose, T., \& Milyo, J. (2005). A measure of media bias. Quarterly Journal of Economics, 120, 1191-1237.

Harrington, D. E. (1989). "Economic news on television: The determinants of coverage." Public Opinion Quarterly, 53, 566-574.

Hibbs Jr., D. A. (1987). The American political economy: Macroeconomics and electoral politics. Cambridge: Harvard University Press.

Iyengar, S., \& Kinder, D. R. (1987). News that matters. Chicago: University of Chicago Press.

Larcinese, V., Puglisi, R., \& Snyder Jr., J. M. 2011. Partisan bias in economic news: Evidence on the agenda-setting behavior of U.S. newspapers. Journal of Public Economics, 95, 1178-1189.

Lott Jr., J. R., \& Hassett, K. A. (2014). "Is newspaper coverage of economic events politically biased? Public Choice, 160, 65-108.

Nadeau, R., Niemi, R. G., Fan, D. P., \& Amato, T. (1999). "Elite economic forecasts, economic news, mass economic judgments, and presidential approval. Journal of Politics, 61, 109-135.

Niven, D. (2002). Partisan bias in the media? A new test. Social Science Quarterly, 80, 847- 857. 
Petrocik, J. R. (1996). Issue ownership in presidential elections, with a 1980 case study. American Journal of Political Science, 40, 825-850.

Petrocik, J. R., Benoit, W. L., \& Hansen, G. J. (2003). Issue ownership and presidential campaigning, 1952-2000. Political Science Quarterly, 118, 599-626.

Powell, G. B., \& Whitten, G. D. (1993). A cross-national analysis of economic voting: Taking account of the political context. American Journal of Political Science, 37, 391-414.

Puglisi, R., \& Snyder Jr., J. M. (2015). The balanced US press. Journal of the European Economic Association, 13, 240-264.

Roberts, M., \& McComb, M. (1994). Agenda-setting and political advertising: Origins of the news agenda. Political Communication, 11, 249-262.

Schiffer, A. J. (2006). Assessing partisan bias in political news: The case(s) of local senate election coverage. Political Communication, 23, 23-39.

Shoemaker, P. J., \& Vos, T. P. (2009). Gatekeeping theory. New York: Routledge.

Soroka, S. N. (2006). Good news and bad news: Asymmetric responses to economic information. Journal of Politics, 68, 372-385.

Soroka, S. N. (2012). The gatekeeping function: Distributions of information in media and the real-world. Journal of Politics, 74, 514-528.

Soroka, S. N. (2014). Negativity in democratic politics: Causes and consequences. Cambridge: Cambridge University Press.

Soroka, S. N., Stecula, D. A., \& Wlezien, C. (2015). It's (change in) the (future) economy, stupid: Economic indicators, the media, and public opinion. American Journal of Political Science, 59, 457-474.

Wlezien, C, Soroka, S. N., \& Stecula, D. A. (2017). A cross-national analysis of the causes and consequences of economic news. Social Science Quarterly, 98, 1010-1025.

Trussler, M., \& Soroka, S. N. (2014). Consumer demand for cynical and negative news frames. International Journal of Press/Politics, 19, 360-379.

Watts, M., Domke, D., Shah, D. V., \& Fan, D. (1999). Elite cues and media bias in presidential campaigns. Communication Research, 26, 144-175.

Young, L., \& Soroka, S.N. (2012). Affective news: The automated coding of sentiment in political texts. Political Communication, 29, 205-231. 